TITLE:

\title{
Instantaneous earthquake input energy and sensitivity in base- isolated building
}

$\operatorname{AUTHOR}(\mathrm{S}):$

Yamamoto, Kaoru; Fujita, Kohei; Takewaki, Izuru

\section{CITATION:}

Yamamoto, Kaoru ... [et al]. Instantaneous earthquake input energy and sensitivity in baseisolated building. The Structural Design of Tall and Special Buildings 2009, 20(6): 631-648

\section{ISSUE DATE:}

2009-10-07

URL:

http://hdl.handle.net/2433/197135

\section{RIGHT:}

This is the peer reviewed version of the following article: amamoto, K. Fuijta, K. and Takewaki, I. (2011), Instantaneous earthquake input energy and sensitivity in base-isolated building. Struct. Design Tall Spec. Build., 20:631-648, which has been published in final form at http://dx.doi.org/10.1002/tal.539; This is not the published version. Please cite only the published version;; この論文は出版社版でありません。引用の際には出版社版をご確認ご利用ください。 


\title{
INSTANTANEOUS EARTHQUAKE INPUT ENERGY AND SENSITIVITY IN BASE-ISOLATED BUILDING
}

\author{
KAORU YAMAMOTO, KOHEI FUJITA AND IZURU TAKEWAKI* \\ Department of Urban and Environmental Engineering, Graduate School of Engineering, \\ Kyoto University, Kyotodaigaku-Katsura, Nishikyo-ku, Kyoto 615-8540, Japan
}

\section{SUMMARY}

The input energy and energy input rate to a base-isolated (BI) building during an earthquake are considered and formulated in the frequency domain. The frequency-domain approach for computation of input energy and energy input rate has different remarkable advantages compared to the conventional time-domain approach. It is demonstrated that the input energy can be of a compact form via the frequency integration of the product between the input component (squared Fourier amplitude spectrum of acceleration) and the structural model component (so-called energy transfer function). Furthermore the energy input rate can also be of a similar form via the frequency integration of the product between the instantaneous power spectrum and the energy transfer function. With the help of this compact form, it is shown that the formulation in the frequency domain is essential for deriving arbitrary-order closed-form sensitivities of the input energy and energy input rate with respect to uncertain stiffness and damping coefficients in the base-isolation story. The closed-form sensitivity expressions provide us with information on the most unfavorable variation of the uncertain parameters which leads to the maximum input energy and input rate.

Keywords: Earthquake input energy, energy input rate, base-isolation, frequency-domain analysis, response sensitivity, parameter uncertainty, instantaneous power spectrum

\footnotetext{
* Professor, Tel.: +81-75-383-3294; fax: +81-75-383-3297, E-mail: takewaki@archi.kyoto-u.ac.jp
} 


\section{INTRODUCTION}

While base-isolation (BI) systems are very useful in reducing the earthquake response of buildings (for example see Barbat et al 1995; Jangid 1995; Meirovitch and Stemple 1997; Jangid and Banerji 1998; Naeim and Kelly 1999; Morales 2003), the BI system has a large variability in its mechanical properties and uncertainty analysis is often implemented in the actual structural design of base-isolated (BI) buildings. For example, the dependence of the mechanical properties of the BI system on temperature, amplitude and velocity of deformation, axial stress of isolators, etc. and the degree of variability of these factors have to be taken into account appropriately. In this sense, uncertainty analysis of BI systems plays a key role in the reliable design of BI buildings.

In this paper, uncertainty in BI buildings and its effect on earthquake input energy and energy input rate are investigated. That uncertainty is assumed to result from the variability in the modeling of mechanical properties of the BI system. For this purpose, a shear building model supported by a BI system is treated. The analysis of BI buildings is well established and some computer programs can be used for the analysis of BI buildings. It is also true that, while the analysis of BI effects has been focused mainly on the investigation in terms of deformation and acceleration, much attention has never been directed to the investigation in terms of the earthquake input energy and energy input rate to the BI building. However, the energy concept may be appropriate especially in the analysis of BI buildings which consist of multiple components with completely different properties (Naeim and Kelly 1999, Austin and Lin 2004). In practice, the energy concept is often used in the preliminary design of BI buildings (AIJ 1989, 2001). This method is referred to as 'an envelope analysis method'.

From this point of view, the earthquake input energy and energy input rate to a BI building are chosen as the response quantities in the evaluation of the effect of the uncertain parameters. The frequency-domain approach is used to evaluate the earthquake input energy and energy input rate in an analytical way. It is shown that the earthquake input energy and energy input rate can be obtained in a compact form by taking advantage of the frequencydomain approach. The energy transfer function necessary in the evaluation of the input 
energy and energy input rate in the frequency domain is obtained in closed form by reducing the multi-degree-of-freedom (MDOF) super-structure into a single-degree-of-freedom (SDOF) system and utilizing an explicit expression of the inverse of the coefficient matrix in the equations of motion. Owing to the introduction of Fourier amplitude spectra of 'truncated ground motions', the computational error does not accumulate even at later times in the frequency-domain formulation.

It is further shown that arbitrary-order sensitivities of the earthquake input energy and energy input rate with respect to uncertain parameters can also be obtained in closed form by taking advantage of the frequency-domain approach. Arbitrary-order sensitivities of the energy transfer function needed in the evaluation of the sensitivity of the earthquake input energy and energy input rate are derived in closed form. Furthermore it is demonstrated that the frequency-domain method has another advantage that the bound analysis of earthquake energy input rate can be implemented easily by using the property of frequency-range integration of the energy transfer function.

Several numerical examples are presented for short and long period ground motion models proposed in this paper in order to investigate the properties of the input energy and energy input rate to BI buildings by various ground motion models.

\section{EARTHQUAKE INPUT ENERGY IN FREQUENCY DOMAIN}

Consider an $N$-story shear building model, as shown in Fig.1, supported by a BI system. Let $m_{i}, k_{i}, c_{i}$ denote the mass of the $(i+1)$-th floor, the stiffness of the $i$-th story and the corresponding damping coefficient, respectively. It is assumed here that the BI system can be modeled by a linear elastic spring and a linear viscous damper justified for BI systems based on linear rubber bearing (LRB) that include systems constituted by LRB and hydraulic oil dampers. Actually there are many base-isolated buildings in Japan and other countries which have natural rubber isolators and oil dampers. These apparatuses can be modeled as linear mechanical systems. It can also be expected that the theory for linear elastic response plays a fundamental role for developing the theory for nonlinear response. 
The horizontal stiffness and the damping coefficient of the BI system are denoted by $k$ and $c$, respectively, and the mass at the BI system is denoted by $m$. This model is subjected to a horizontal acceleration $\ddot{u}_{g}(t)$ at the ground surface. Let $u_{i}$ denote the horizontal displacement of the $(i+1)$-th floor relative to the ground. The equations of motion for this BI building may be expressed as

$$
\mathbf{M u ̈}+\mathbf{C u}+\mathbf{K u}=-\mathbf{M} 1 \ddot{u}_{g}
$$

where $\mathbf{u}=\left\{\begin{array}{lll}u_{0} & u_{1} \cdots u_{N}\end{array}\right\}^{T}$. M, K, $\mathbf{C}$ and $\mathbf{1}$ are the following mass, stiffness and damping matrices and influence coefficient vector, respectively.

$$
\begin{aligned}
& \mathbf{M}=\operatorname{diag}\left(m m_{1} \cdots m_{N}\right) \\
& \mathbf{K}=\left[\begin{array}{cccc}
k+k_{1} & -k_{1} & & \mathbf{0} \\
-k_{1} & \ddots & \ddots & \\
& \ddots & k_{N-1}+k_{N} & -k_{N} \\
\mathbf{0} & & -k_{N} & k_{N}
\end{array}\right], \mathbf{C}=\left[\begin{array}{cccc}
c+c_{1} & -c_{1} & & \mathbf{0} \\
-c_{1} & \ddots & \ddots & \\
& \ddots & c_{N-1}+c_{N} & -c_{N} \\
\mathbf{0} & & -c_{N} & c_{N}
\end{array}\right] \\
& \mathbf{1}=\left\{\begin{array}{lll}
1 & 1 & \cdots
\end{array}\right\}^{T}
\end{aligned}
$$

\subsection{Reduction of MDOF super-structure into SDOF model}

For simplicity of expression, let us reduce the super-structure into an SDOF model as shown in Fig.2 (Hino et al. 2008). The reduced mass, stiffness and damping coefficient of the super-structure are denoted by $M, K, C$, respectively. Then the total system becomes a 2DOF system. The accuracy of this model has been clarified and guaranteed in the reference (Hino et al. 2008). Since the present paper focuses on BI buildings except super high-rise buildings, this approximation seems reasonable. Let $\mathbf{M}, \mathbf{K}, \mathbf{C}$ denote the mass, stiffness and damping matrices of this 2-DOF system and let $\mathbf{1}, \mathbf{u}(t)$ denote the vector $\left\{\begin{array}{ll}1 & 1\end{array}\right\}^{T}$ and the horizontal displacement vector of this 2-DOF system. The equations of motion in the frequency domain of this 2-DOF system may be expressed by

$$
\mathbf{A U}(\omega)=-\mathbf{M} 1 \ddot{U}_{g}(\omega)
$$


where $\mathbf{A} \equiv-\omega^{2} \mathbf{M}+\mathrm{i} \omega \mathbf{C}+\mathbf{K}$ and $\mathbf{U}(\omega), \ddot{U}_{g}(\omega)$ are the Fourier transforms of $\mathbf{u}(t)$ and $\ddot{u}_{g}(t)$, respectively.

\subsection{Earthquake input energy until an arbitrary time and energy input rate}

The earthquake input energy until time $t$ may be expressed by

$$
E_{I}(t)=-\int_{0}^{t} \dot{\mathbf{u}}(\tau)^{T} \mathbf{M} 1 \ddot{u}_{g}(\tau) d \tau
$$

Uang and Bertero (1990) discussed the difference between the absolute energy and relative energy expressed by Eq.(4) and derived an insightful conclusion mainly from the viewpoint of inelastic response. This discussion is very important and careful treatment may be necessary depending on the type of ground motion (near-field or far-field, etc.) and the relation of the predominant frequency of ground motions with the structural natural frequency (Uang and Bertero 1990; Takewaki 2006). It is also known that the actual energy input expressed better by the absolute energy can be captured by the energy input rate or instantaneous input energy. Since both the total input energy related to the relative energy and the energy input rate are treated in this paper, the relative energy is treated at first. If the final input time of $\ddot{u}_{g}(t)$ is denoted by $t_{0}, E_{I}\left(t_{0}\right)$ indicates the total input energy (Housner 1959; Housner and Jennings 1977; Akiyama 1985; Uang and Bertero 1990; Trifunac et al. 2001; Takewaki 2004a, b).

Let us define modified ground motion $\hat{\ddot{u}}_{g}(\tau ; t)$ at time $\tau$ which has the same component until time $t$ and null component after time $t$ (see Fig.3, Ohi et al. 1991, Takewaki 2005b). The response velocity at time $\tau$ corresponding to $\hat{\ddot{u}}_{g}(\tau ; t)$ is denoted by $\hat{\dot{\mathbf{u}}}(\tau ; t)$. The Fourier transforms of $\hat{\ddot{u}}_{g}(\tau ; t)$ and $\hat{\dot{\mathbf{u}}}(\tau ; t)$ are expressed by $\hat{\ddot{U}}_{g}(\omega ; t), \hat{\dot{\mathbf{U}}}(\omega ; t)$, respectively. It is noted that $\hat{\tilde{U}}_{g}\left(\omega ; t_{0}\right)=\ddot{U}_{g}(\omega)$.

By introducing the truncated ground motion and the corresponding velocity response and extending the integration limits, Eq.(4) can be rewritten as

$$
E_{I}(t)=-\int_{-\infty}^{\infty} \hat{\dot{\mathbf{u}}}(\tau ; t)^{T} \mathbf{M} 1 \hat{\ddot{u}}_{g}(\tau ; t) d \tau
$$


Applying the Fourier and inverse Fourier transformations (Lyon 1975; Ohi et al. 1985; Kuwamura et al. 1994; Ordaz et al. 2003; Takewaki 2004a, b), Eq.(5) may be rearranged into

$$
\begin{aligned}
E_{I}(t) & =-\int_{-\infty}^{\infty} \frac{1}{2 \pi} \int_{-\infty}^{\infty} \hat{\dot{\mathbf{U}}}(\omega ; t)^{T} e^{\mathrm{i} \omega \tau} \mathbf{M} 1 \hat{\ddot{u}}_{g}(\tau ; t) d \omega d \tau \\
& =\frac{1}{2 \pi} \int_{-\infty}^{\infty} \mathrm{i} \omega \mathbf{1}^{T} \mathbf{M}^{T} \mathbf{A}^{-1} \hat{\tilde{U}}_{g}(\omega ; t) \mathbf{M} \mathbf{1} \hat{\ddot{U}}_{g}(-\omega ; t) d \omega \\
& =\int_{0}^{\infty}\left|\hat{\tilde{U}}_{g}(\omega ; t)\right|^{2} F(\omega) d \omega
\end{aligned}
$$

where $\left|\hat{\tilde{U}}_{g}(\omega ; t)\right|^{2}$ is referred to as the squared Fourier amplitude spectrum (SFAS) hereafter. In Eq.(6), the relation $\hat{\dot{\mathbf{U}}}(\omega ; t)=-\mathbf{i} \omega \mathbf{A}^{-1} \mathbf{M} 1 \hat{\tilde{U}}_{g}(\omega ; t)$ is used and $F(\omega)$ is defined by

$$
F(\omega) \equiv \operatorname{Re}\left[\mathrm{i} \omega \mathbf{1}^{T} \mathbf{M}^{T} \mathbf{A}^{-1} \mathbf{M} \mathbf{1}\right] / \pi
$$

Since $\hat{\tilde{U}}_{g}\left(\omega ; t_{0}\right)=\ddot{U}_{g}(\omega)$, it follows that

$$
E_{I}\left(t_{0}\right)=\int_{0}^{\infty}\left|\ddot{U}_{g}(\omega)\right|^{2} F(\omega) d \omega
$$

From Eq.(6), the earthquake energy input rate $d E_{I}(t) / d t$ may be expressed by

$$
\frac{d E_{I}(t)}{d t}=\int_{0}^{\infty}\left(d\left|\hat{\tilde{U}}_{g}(\omega ; t)\right|^{2} / d t\right) F(\omega) d \omega
$$

This expression was derived first by Ohi et al. (1991) and was pointed out that $d\left|\hat{\tilde{U}}_{g}(\omega ; t)\right|^{2} / d t$ is equivalent to the instantaneous power spectrum introduced by Page (1952).

\subsection{Arbitrary-order sensitivities of input energy and maximum energy input rate}

\subsubsection{Arbitrary-order sensitivities of input energy}

An arbitrary-order sensitivity of earthquake input energy may be expressed by

$$
\frac{\partial^{m+n} E_{I}}{\partial c^{m} \partial k^{n}}=\int_{0}^{\infty}\left|\hat{\ddot{U}}_{g}(\omega ; t)\right|^{2} \frac{\partial^{m+n} F(\omega)}{\partial c^{m} \partial k^{n}} d \omega
$$

In Eq.(10), an arbitrary-order sensitivity of the energy transfer function may be provided by 


$$
\frac{\partial^{m+n} F(\omega)}{\partial c^{m} \partial k^{n}}=\frac{1}{\pi} \operatorname{Re}\left[\mathrm{i} \omega \mathbf{1}^{T} \mathbf{M}^{T} \frac{\partial^{m+n} \mathbf{A}^{-1}}{\partial c^{m} \partial k^{n}} \mathbf{M} \mathbf{1}\right]
$$

An arbitrary-order sensitivity of $\mathbf{A}^{-1}$ can be derived as follows. By differentiating both sides of $\mathbf{A} \mathbf{A}^{-1}=\mathbf{I}$ by an uncertain parameter, the following relation can be obtained.

$$
\mathbf{A}^{\prime} \mathbf{A}^{-1}+\mathbf{A}\left(\mathbf{A}^{-1}\right)^{\prime}=\mathbf{0}
$$

From Eq.(12), the sensitivity of $\mathbf{A}^{-1}$ can be expressed by

$$
\left(\mathbf{A}^{-1}\right)^{\prime}=-\mathbf{A}^{-1} \mathbf{A}^{\prime} \mathbf{A}^{-1}
$$

Implementation of $\mathbf{A}^{\prime}$ and multiplication $\mathbf{A}^{-1} \mathbf{A}^{\prime} \mathbf{A}^{-1}$ in Eq.(13) provide

$$
\begin{aligned}
& \frac{\partial \mathbf{A}^{-1}}{\partial k}=-\alpha^{-2} \mathbf{Z} \\
& \frac{\partial \mathbf{A}^{-1}}{\partial c}=-\mathrm{i} \omega \alpha^{-2} \mathbf{Z}
\end{aligned}
$$

where

$$
\begin{aligned}
& \alpha=\omega^{4} M m-\omega^{2}\{M(K+k)+C c+m K\}+K k+\mathrm{i}\left[-\omega^{3}\{M(C+c)+m C\}+\omega(C k+c K)\right] \\
& \mathbf{Z}=\left[\begin{array}{ll}
a & b \\
b & d
\end{array}\right] \\
& a=\omega^{4} M^{2}-\omega^{2}\left(C^{2}+2 M K\right)+K^{2}+2 \mathrm{i} \omega C\left(K-\omega^{2} M\right) \\
& b=K^{2}-\omega^{2}\left(M K+C^{2}\right)+\mathrm{i} \omega\left(2 C K-\omega^{2} M C\right) \\
& d=K^{2}-\omega^{2} C^{2}+2 \mathrm{i} \omega C K
\end{aligned}
$$

Similarly the second-order sensitivity of $\mathbf{A}^{-1}$ may be derived as

$$
\left(\mathbf{A}^{-1}\right)^{\prime \prime}=-\mathbf{A}^{-1}\left(2 \mathbf{A}^{\prime}\left(\mathbf{A}^{-1}\right)^{\prime}+\mathbf{A}^{\prime \prime} \mathbf{A}^{-1}\right)
$$

Since $\mathbf{A}^{\prime}=$ const., $\mathbf{A}^{\prime \prime}=\mathbf{0}$. Therefore $\left(\mathbf{A}^{-1}\right)^{\prime \prime}$ can be expressed as

$$
\left(\mathbf{A}^{-1}\right)^{\prime \prime}=-2 \mathbf{A}^{-1} \mathbf{A}^{\prime}\left(\mathbf{A}^{-1}\right)^{\prime}
$$


Repeated application of this procedure provides

$$
\left(\mathbf{A}^{-1}\right)^{(n)}=-n \mathbf{A}^{-1} \mathbf{A}^{\prime}\left(\mathbf{A}^{-1}\right)^{(n-1)}
$$

where ()$^{(n)}$ denotes the $n$-th order differentiation with respect to an uncertain parameter. Recursive application of Eq.(18) leads to

$$
\left(\mathbf{A}^{-1}\right)^{(n)}=(-1)^{n} n !\left\{\mathbf{A}^{-1} \mathbf{A}^{\prime}\right\}^{n} \mathbf{A}^{-1}
$$

This was derived in Refs. (Takewaki 2005a, Kishida and Takewaki 2006). Substitution of the expression of $\mathbf{A}^{-1}$ and application of stiffness and damping parameters as uncertain paremeters into Eq.(19) may provide

$$
\begin{aligned}
& \frac{\partial^{n} \mathbf{A}^{-1}}{\partial k^{n}}=(-1)^{n} n ! \alpha^{-(n+1)}\left(-\omega^{2} M+\mathrm{i} \omega C+K\right)^{n-1} \mathbf{Z} \\
& \frac{\partial^{n} \mathbf{A}^{-1}}{\partial c^{n}}=(-\mathrm{i} \omega)^{n} n ! \alpha^{-(n+1)}\left(-\omega^{2} M+\mathrm{i} \omega C+K\right)^{n-1} \mathbf{Z}
\end{aligned}
$$

Differentiation of $\mathbf{A}^{-1}$ with respect to both stiffness and damping parameters can be derived by differentiating Eq.(20a) $m$ times by the damping coefficient $c$.

$$
\frac{\partial^{m+n} \mathbf{A}^{-1}}{\partial c^{m} \partial k^{n}}=(-1)^{n} n ! \frac{\partial^{m} \alpha^{-(n+1)}}{\partial c^{m}}\left(-\omega^{2} M+\mathrm{i} \omega C+K\right)^{n-1} \mathbf{Z}
$$

From Eq. (15a), it is noted that

$$
\frac{\partial \alpha}{\partial c}=\mathrm{i} \omega\left(-\omega^{2} M+\mathrm{i} \omega C+K\right), \quad \frac{\partial^{2} \alpha}{\partial c^{2}}=0
$$

Using Eqs.(22a, b), the term $\partial^{m} \alpha^{-(n+1)} / \partial c^{m}$ can be derived as

$$
\begin{aligned}
\frac{\partial^{m} \alpha^{-(n+1)}}{\partial c^{m}} & =(-1)^{m} \frac{(m+n) !}{n !} \alpha^{-(m+n+1)}\left(\frac{\partial \alpha}{\partial c}\right)^{m} \\
& =(-1)^{m}(\mathrm{i} \omega)^{m} \frac{(m+n) !}{n !} \alpha^{-(m+n+1)}\left(-\omega^{2} M+\mathrm{i} \omega C+K\right)^{m}
\end{aligned}
$$

Substitution of Eq.(23) into Eq.(21) provides 


$$
\frac{\partial^{m+n} \mathbf{A}^{-1}}{\partial c^{m} \partial k^{n}}=(-1)^{m+n}(\mathrm{i} \omega)^{m}(m+n) ! \alpha^{-(m+n+1)}\left(-\omega^{2} M+\mathrm{i} \omega C+K\right)^{m+n-1} \mathbf{Z}
$$

In order to obtain $\partial^{m+n} F(\omega) / \partial c^{m} \partial k^{n}$ in Eq.(11), Eq.(24) can be substituted into Eq.(11).

By substituting the obtained expressions $\partial^{n} E_{I} / \partial k^{n}, \partial^{n} E_{I} / \partial c^{n}$ and $\partial^{n} E_{I} / \partial k^{j} \partial c^{n-j}$ in the Taylor series expansion, the earthquake input energy around the nominal stiffness and damping coefficients, $k$ and $c$, can be expressed as

$$
\begin{aligned}
& E_{I}(k+\Delta k)=E_{I}(k)+\sum_{n} \frac{k^{n}}{n !} \frac{\partial^{n} E_{I}}{\partial k^{n}}\left(\frac{\Delta k}{k}\right)^{n} \\
& E_{I}(c+\Delta c)=E_{I}(c)+\sum_{n} \frac{c^{n}}{n !} \frac{\partial^{n} E_{I}}{\partial c^{n}}\left(\frac{\Delta c}{c}\right)^{n} \\
& E_{I}(k+\Delta k, c+\Delta c)=E_{I}(k, c)+\sum_{n} \frac{1}{n !} \sum_{j=0}^{n}{ }_{n} C_{j} c^{j} k^{n-j} \frac{\partial^{n} E_{I}}{\partial k^{j} \partial c^{n-j}}\left(\frac{\Delta c}{c}\right)^{j}\left(\frac{\Delta k}{k}\right)^{n-j}
\end{aligned}
$$

\subsubsection{Arbitrary-order sensitivities of energy input rate}

Arbitrary sensitivities of earthquake energy input rate with respect to stiffness and damping parameters may be expressed as

$$
\begin{aligned}
& \frac{\partial^{n}}{\partial k^{n}} \frac{d E_{I}}{d t}=\int_{0}^{\infty} \frac{d\left|\hat{\tilde{U}}_{g}(\omega ; t)\right|^{2}}{d t} \frac{\partial^{n} F(\omega)}{\partial k^{n}} d \omega \\
& \frac{\partial^{n}}{\partial c^{n}} \frac{d E_{I}}{d t}=\int_{0}^{\infty} \frac{d\left|\hat{\tilde{U}}_{g}(\omega ; t)\right|^{2}}{d t} \frac{\partial^{n} F(\omega)}{\partial c^{n}} d \omega \\
& \frac{\partial^{m+n}}{\partial c^{m} \partial k^{n}} \frac{d E_{I}}{d t}=\int_{0}^{\infty} \frac{d\left|\hat{\tilde{U}}_{g}(\omega ; t)\right|^{2}}{d t} \frac{\partial^{m+n} F(\omega)}{\partial c^{m} \partial k^{n}} d \omega
\end{aligned}
$$

Since the expressions $\partial^{n} F(\omega) / \partial k^{n}, \partial^{n} F(\omega) / \partial c^{n}$ and $\partial^{m+n} F(\omega) / \partial c^{m} \partial k^{n}$ in Eqs.(26a-c) have been derived above, the earthquake energy input rate around the nominal stiffness and damping parameters, $k$ and $c$, can be expressed as 


$$
\begin{aligned}
& \frac{d E_{I}}{d t}(k+\Delta k)=\frac{d E_{I}}{d t}(k)+\sum_{n} \frac{k^{n}}{n !}\left(\frac{\partial^{n}}{\partial k^{n}} \frac{d E_{I}}{d t}\right)\left(\frac{\Delta k}{k}\right)^{n} \\
& \frac{d E_{I}}{d t}(c+\Delta c)=\frac{d E_{I}}{d t}(c)+\sum_{n} \frac{c^{n}}{n !}\left(\frac{\partial^{n}}{\partial c^{n}} \frac{d E_{I}}{d t}\right)\left(\frac{\Delta c}{c}\right)^{n} \\
& \frac{d E_{I}}{d t}(k+\Delta k, c+\Delta c)=\frac{d E_{I}}{d t}(k, c)+\sum_{n} \frac{1}{n !} \sum_{j=0}^{n}{ }_{n} C_{j} c^{j} k^{n-j}\left(\frac{\partial^{n}}{\partial k^{j} \partial c^{n-j}} \frac{d E_{I}}{d t}\right)\left(\frac{\Delta c}{c}\right)^{j}\left(\frac{\Delta k}{k}\right)^{n-j}
\end{aligned}
$$

\section{MAXIMUM ACCELERATION IN SUPER-BUILDING}

The mean-square absolute acceleration at the super-building subjected to a ground motion with PSD function $S_{g}(\omega)$ can be expressed by

$$
\sigma_{A}^{2}=\int_{-\infty}^{\infty}\left|H_{2}(\omega)\right|^{2} S_{g}(\omega) d \omega=\int_{-\infty}^{\infty} H_{2}(\omega) H_{2}^{*}(\omega) S_{g}(\omega) d \omega
$$

where $H_{2}(\omega)$ is the second component of $\mathbf{H}(\omega)$ defined by $\mathbf{H}(\omega)=\left(\mathbf{I}+\omega^{2} \mathbf{A}^{-1} \mathbf{M}\right) \mathbf{1}$ and ( ) ${ }^{*}$ denotes the complex conjugate.

An arbitrary-order sensitivity of the mean-square absolute acceleration at the superbuilding may be derived as

$$
\frac{\partial^{m+n} \sigma_{A}^{2}}{\partial c^{m} \partial k^{n}}=\int_{-\infty}^{\infty}\left\{\sum_{j=0}^{n}{ }_{n} C_{j} \sum_{l=0}^{m}{ }_{m} C_{l} \frac{\partial^{n-j+l} H_{2}(\omega)}{\partial c^{l} \partial k^{n-j}} \frac{\partial^{j+m-l} H_{2}^{*}(\omega)}{\partial c^{m-l} \partial k^{j}}\right\} S_{g}(\omega) d \omega
$$

The sensitivities of the acceleration transfer function in Eq.(29) may be obtained as

$$
\begin{aligned}
& \frac{\partial^{m+n} \mathbf{H}(\omega)}{\partial c^{m} \partial k^{n}}=\omega^{2} \frac{\partial^{m+n} \mathbf{A}^{-1}}{\partial c^{m} \partial k^{n}} \mathbf{M} \mathbf{1} \\
& =\omega^{2}(-1)^{m+n}(\mathrm{i} \omega)^{m}(m+n) ! \alpha^{-(m+n+1)}\left(-\omega^{2} M+\mathrm{i} \omega C+K\right)^{m+n-1} \mathbf{Z M 1}
\end{aligned}
$$

Using Eq.(29), the mean-square absolute acceleration at the super-building around the nominal values, $k$ and $c$, of stiffness and damping coefficients may be expressed as

$$
\sigma_{A}^{2}(k+\Delta k)=\sigma_{A}^{2}(k)+\sum_{n} \frac{k^{n}}{n !} \frac{\partial^{n} \sigma_{A}^{2}}{\partial k^{n}}\left(\frac{\Delta k}{k}\right)^{n}
$$




$$
\begin{aligned}
& \sigma_{A}^{2}(c+\Delta c)=\sigma_{A}^{2}(c)+\sum_{n} \frac{c^{n}}{n !} \frac{\partial^{n} \sigma_{A}^{2}}{\partial c^{n}}\left(\frac{\Delta c}{c}\right)^{n} \\
& \sigma_{A}^{2}(k+\Delta k, c+\Delta c)=\sigma_{A}^{2}(k, c)+\sum_{n} \frac{1}{n !} \sum_{j=0}^{n}{ }_{n} C_{j} c^{j} k^{n-j} \frac{\partial^{n} \sigma_{A}^{2}}{\partial k^{j} \partial c^{n-j}}\left(\frac{\Delta c}{c}\right)^{j}\left(\frac{\Delta k}{k}\right)^{n-j}
\end{aligned}
$$

Although a 2DOF model has been used to derive a closed-form sensitivity expression, the numerical evaluation of higher-order sensitivity and variation to model uncertainties may be possible as shown in the reference (Kishida and Takewaki 2006).

\section{BOUNDING ANALYSIS OF ENERGY INPUT RATE VIA FREQUENCY-DOMAIN FORMULATION}

The frequency-domain method has another advantage. Assume that the time rate of squared Fourier amplitude spectrum of the truncated ground acceleration is bounded as $\max _{t}\left(d\left|\hat{\tilde{U}}_{g}(\omega ; t)\right|^{2} / d t\right) \leq D^{U}$ (Fig. 4(a)). It can then be shown that the earthquake energy input rate $d E_{I} / d t$ can be bounded by the following relation.

$$
\max _{t}\left(\frac{d E_{I}}{d t}\right) \leq \frac{1}{2}(M+m) D^{U}
$$

This relation can be derived from the property $\int_{0}^{\infty} F(\omega) d \omega=(M+m) / 2$ (Takewaki and Fujita, 2008).

In another case, assume that $d\left|\hat{\tilde{U}}_{g}(\omega ; t)\right|^{2} / d t$ is bounded as (see Fig. 4(b)).

$$
\max _{t}\left(d\left|\hat{\tilde{U}}_{g}(\omega ; t)\right|^{2} / d t\right) \leq \begin{cases}D_{0}+D_{V}(\omega) & \left(0 \leq \omega \leq \omega_{C}\right) \\ D_{0} & \left(\omega_{C} \leq \omega\right)\end{cases}
$$

Then the earthquake energy input rate $d E_{I} / d t$ can be bounded by the following relation.

$$
\max _{t}\left(\frac{d E_{I}}{d t}\right) \leq \frac{1}{2}(M+m) D_{0}+\int_{0}^{\omega_{C}} F(\omega) D_{V}(\omega) d \omega
$$

The second term in the right-hand side can be evaluated numerically. Since the earthquake ground motion is very uncertain, these bounding relations are expected to be useful for 
estimating the upper bound of the earthquake energy input rate. This bound estimate is difficult in the time-domain method.

\section{NUMERICAL EXAMPLES}

\subsection{Base-isolated building model}

Numerical examples for a 10-story shear building model with the BI system are presented. The story stiffnesses of the building are determined so that the 10-story shear building model with fixed-base has the fundamental natural periods of $1.0(\mathrm{~s})$ and the lowest eigenmode of the model with fixed-base is straight. As a result, the lowest eigenmode (superstructural part) of the BI building is not straight. This treatment is based on the inverse problem approach (Nakamura and Yamane 1986). It is also assumed that the damping matrix of the super-structure with fixed base is proportional to the stiffness matrix of the superstructure and the damping ratio in the lowest mode of the super-structure with fixed base is 0.02. The stiffness $k$ and damping coefficient $c$ of the BI system have been determined so that the fundamental natural period of the BI building is 5.3(s) (see Takewaki 1998 for hybrid inverse problem for rigid building stiffnesses) and the damping ratio of the BI rigid building model is 0.2. The parameters of the building and the BI system are summarized in Table I.

\subsection{Example 1 (Model of SFAS of truncated ground motion and uncertainty analysis)}

An example of SFAS $\left|\hat{\tilde{U}}_{g}(\omega ; t)\right|^{2}$ of truncated ground motions can be expressed by

$$
\left|\hat{\tilde{U}}_{g}(\omega ; t)\right|^{2}=\left\{\begin{array}{l}
2 \pi t \cdot S_{u}(\omega, t)=2 \pi t \cdot a\left(e^{-b_{1} t}-e^{-b_{2} t}\right) S(\omega) \quad\left(0 \leq t \leq t_{0}\right) \\
2 \pi t_{0} \cdot S_{u}\left(\omega, t_{0}\right)=2 \pi t_{0} \cdot a\left(e^{-b_{1} t_{0}}-e^{-b_{2} t_{0}}\right) S(\omega) \quad\left(t \geq t_{0}\right)
\end{array}\right.
$$

where $t_{0}$ is the terminal time (duration) of input and $S(\omega)$ denotes

$$
S(\omega)=\left\{\frac{\Omega^{4}+4 \zeta^{2} \Omega^{2} \omega^{2}}{\left[\omega^{2}-\Omega^{2}\right]^{2}+4 \zeta^{2} \Omega^{2} \omega^{2}}\right\} S_{0}
$$

In Eq.(36), $\Omega$ and $\zeta$ are the predominant circular frequency and damping parameter. 
The parameter $a$ in Eq.(35) characterizing the intensity of the ground motion is determined from the constraint on acceleration power.

$$
\begin{aligned}
\bar{C}_{A} & =\int_{-\infty}^{\infty} \ddot{u}_{g}(t)^{2} d t=\frac{1}{\pi} \int_{0}^{\infty}\left|\ddot{U}_{g}(\omega)\right|^{2} d \omega=\frac{1}{\pi} \int_{0}^{\infty}\left|\hat{\ddot{U}}_{g}\left(\omega ; t_{0}\right)\right|^{2} d \omega \\
& =2 \pi t_{0} \cdot a\left(e^{-b_{1} t_{0}}-e^{-b_{2} t_{0}}\right) \int_{0}^{\infty} S(\omega) d \omega
\end{aligned}
$$

In this paper, the short period models and long period models are taken into account. Table II shows the parameters for these ground motion models. The long period models simulate a pulse wave due to near-field ground motions (Hall et al. 1995; Heaton et al. 1995; Jangid and Kelly 2001) or a long-period ground motion resulting from surface waves (Irikura et al. 2004; Ariga et al. 2006). The short period model 1 (predominant period=0.6s) is treated here as the standard model and the parameter $a$ for this model has been determined so that the maximum value of the Fourier amplitude spectrum at the predominant circular frequency $\Omega=2 \pi / 0.6[\mathrm{rad} / \mathrm{s}]$ attains the value $3[\mathrm{~m} / \mathrm{s}$ ] computed for El Centro NS (Imperial Valley 1940). The damping parameter $\zeta$ is set to 0.4 and $S_{0}=0.2\left(\mathrm{~m}^{2} / \mathrm{s}^{3}\right)$.

Fig. 5 shows the energy transfer function $F(\omega)$ for this BI building. The unit of the ordinate is $\mathrm{N} \cdot \mathrm{s}^{3} / \mathrm{m}$. It can be observed that $F(\omega)$ has a peak around the fundamental natural circular frequency of the BI building (1.19rad/s). Figs.6(a) and (b) illustrate the first-order sensitivities of the energy transfer function $F(\omega)$ with respect to the stiffness and damping coefficients in the BI story. It can be observed that, while the stiffness sensitivity $\partial F(\omega) / \partial k$ takes comparable positive and negative peak values, the damping sensitivity $\partial F(\omega) / \partial c$ can take a large negative peak value around the fundamental natural circular frequency of the BI building. This is because, while the fundamental natural frequency of the BI model giving the peak value of the energy transfer function shifts to a higher value according to the variation of the BI stiffness, that does not change in the case of the variation of the BI damping. More specifically the frequency corresponding to the peak value shifts to the positive direction, the sensitivity in the range of frequency lower than the fundamental natural frequency of the BI model becomes negative and that in the range of frequency higher than the fundamental natural frequency of the BI model becomes positive. 
Furthermore Figs.7(a) and (b) illustrate the second-order sensitivities of the energy transfer function $F(\omega)$ with respect to the stiffness and damping coefficients in the BI story. It can be seen that, while the second-order sensitivity with respect to $k$ exhibits a large negative peak around the fundamental natural circular frequency of the BI building, that with respect to $c$ does a large positive peak around that.

Fig.8 shows the time history of SFAS $\left|\hat{\tilde{U}}_{g}(\omega ; t)\right|^{2}$ at $18(\mathrm{rad} / \mathrm{s})$ of truncated ground motions extracted from El Centro NS 1940 and the corresponding time history of short period model 1 . It can be seen that the short period model 1 can simulate very well the time history of SFAS $\left|\hat{\ddot{U}}_{g}(\omega ; t)\right|^{2}$ of truncated motions extracted from El Centro NS 1940.

Fig.9(a) illustrates the time histories of input energy for various ground motion models. It can be observed that the total earthquake input energy by the long period model 2 (predominant period=5.3(s)) is the largest and those by the long period models 1 and 3 are the next. On the other hand, the total earthquake input energies by the short period models are rather small. It should be noted that the long period model 2 has a predominant period resonant to the fundamental natural period of the BI building. This means that the resonance of the fundamental natural period of the BI building with the predominant period of ground motions is one of the key issues in the evaluation of input energy to BI buildings.

Fig.9(b) shows the time histories of energy input rate for various ground motion models. It is found that the maximum energy input rate by the long period model 2 is the largest and those by the long period models 1 and 3 are the next. Although the maximum energy input rates by the short period models are small, that by short period model 2 is comparable to that by the long period models 1 and 3. It should also be noted that the large energy input rate continues for a long time (almost 150s) in the long period models and large energy input can be predicted in the long period models from this figure. As in the case of input energy, the resonance of the fundamental natural period of the BI building with the predominant period of ground motions seems to be one of the key issues in the evaluation of energy input rate to BI buildings. 
Fig.10(a) presents the variation of the maximum energy input rate at $t=55.8$ (s) by first and second-order approximations under the long period model 2. The parameter $\Delta c / c$ indicates the ratio of the change of the damping coefficient in the BI story to its nominal value. The parameters $\Delta c / c=-0.5,0.0,1.0$ correspond to half the nominal value, the nominal value and double the nominal value, respectively. It can be observed that the second-order approximation can simulate the actual one in a wider range of the damping coefficient of the BI system and the introduction of damping in the BI story is effective for reduction of the maximum energy input rate of the BI building under a resonant long period motion. In Fig.10(a), the energy input rate by the full 11DOF model (ten-story super building) is also plotted for identifying the accuracy of the 2DOF approximation. It can be seen that the maximum discrepancy between the 2DOF model and the 11DOF model is 2-3\%. Without the present closed-form higher-order sensitivities of the maximum energy input rate, a lot of computational simulations would be required for various damping coefficients in the BI story and many simulated ground motions for the long period model 2.

Fig.10(b) illustrates the variation of the mean-square of top acceleration by first, second, third and fourth-order approximations under El Centro NS 1940. An approximate PSD function of El Centro NS 1940 has been substituted in Eqs.(28) and (29). It can be understood that the fourth-order approximation can simulate the actual one in a wider range of the damping coefficient of the BI system. However the degree of nonlinearity is rather large.

On the other hand, Fig.11(a) shows the variation of the maximum energy input rate with respect to stiffness in the base-isolation story. It can be observed that the first-order approximation exhibits a fairly good result in the range from $\Delta k / k=-0.3$. to 0.3. As in Fig.10(a), the energy input rate by the full 11DOF model is also plotted in Fig.11(a) for identifying the accuracy of the 2DOF approximation. It can be seen that the maximum discrepancy between the 2DOF model and the 11DOF model is 2-3\% again. Fig.11(b) illustrates the variation of the maximum acceleration with respect to stiffness in the baseisolation story. It can be seen that the first-order approximation has a fairly good performance in the range from $\Delta k / k=-0.5$. to 1.0 . 


\subsection{Example 2 (Detailed analysis of SFAS of truncated ground motion and comparison of time-domain and frequency-domain analyses)}

Fig.12 presents the frequency distributions of SFAS $\left|\hat{\tilde{U}}_{g}(\omega ; t)\right|^{2}$ of El Centro NS (Imperial Valley 1940) truncated at (a) 2.5s, (b) 5.0s, (c) 20.0s, (d) 40.0s. It can be observed that, while a blunted spectrum is seen in the motions truncated at early stages, a sharp spectrum can be found in the motions truncated at later stages. It can also be understood that the intensity becomes larger as the truncated time passes.

Fig.13 illustrates the frequency distributions of the time-rates $\partial\left|\hat{\tilde{U}}_{g}(\omega ; t)\right|^{2} / \partial t$ of SFAS of El Centro NS 1940 truncated at (a) 2.5s, (b) 5.0s, (c) 20.0s, (d) 40.0s). As in Fig.12, it can be observed that, while a blunted time-rate spectrum is seen in the motions truncated at early stages, a sharp spectrum can be found in the motions truncated at later stages. On the other hand, the intensity is largest at the intermediate truncated time different from the case for SFAS $\left|\hat{\tilde{U}}_{g}(\omega ; t)\right|^{2}$.

Fig.14 shows sample accelerations of a simulated non-stationary ground motion and a stationary ground motion. The stationary motion has also been generated to clarify the property of $\left|\hat{\tilde{U}}_{g}(\omega ; t)\right|^{2}$ through the comparison with that for the non-stationary motion. This simulated stationary ground motion has been generated by the sum of sine waves with a band limited PSD function of $0.03\left(\mathrm{~m}^{2} / \mathrm{s}^{3}\right)$ in the frequency range $0.1-5.1(\mathrm{rad} / \mathrm{s})$ instead of Eq.(36). On the other hand, the non-stationary motion has been multiplied by an envelope function given by Eq.(35) with parameters $a=2.32, b_{1}=0.09, b_{2}=1.49$. These simulated ground motions enable one to compare (i) the time histories of earthquake input energy computed by the timedomain method (Eq.(4)) and the frequency-domain method (Eq.(6)) and (ii) the time histories of energy input rate computed by the time-domain method $\left(d E_{I}(t) / d t=-\dot{\mathbf{u}}(t)^{T} \mathbf{M} 1 \ddot{u}_{g}(t)\right)$ and the frequency-domain method (Eq.(9)). This comparison may be difficult in the model described by Eqs.(35) and (36) because it does not seem easy to obtain the corresponding time history of ground motion acceleration. 
Fig.15 illustrates the 3D view of average SFAS of 100 ground motions truncated at continuously increasing time ((a) non-stationary, (b) stationary)). A characteristic similar to Fig.12 (blunted spectrum at early stages and sharp spectrum at later stages) can be observed in both figures. It can also be seen that, since the non-stationary motion with high intensity almost end at 20(s), the averaged frequency distributions of SFAS do not change much after the truncated time around 20(s).

Fig.16(a) shows the comparison of the time histories of earthquake input energy computed by the time-domain method (Eq.(4)) and the frequency-domain method (Eq.(6)) for a non-stationary ground motion. In Fig.16(a), the plots by the time-domain method with different computational time increments $(d t=0.005,0.01,0.02 \mathrm{~s})$ are also illustrated. It can be observed that, while the accuracy of the time-domain method depends largely on the computational time increment, the frequency-domain method exhibits a stable result close to the result for $d t=0.005$ assuring more exact one. Furthermore, it should be kept in mind that, owing to the introduction of Fourier amplitude spectra of truncated ground motions, the computational error does not accumulate even at later times in the frequency-domain formulation.

Fig.16(b) illustrates the comparison of the time histories of energy input rate computed by the time-domain method $\left(d E_{I}(t) / d t=-\dot{\mathbf{u}}(t)^{T} \mathbf{M} 1 \ddot{u}_{g}(t)\right)$ and the frequency-domain method (Eq.(9)) for a non-stationary ground motion. It can be observed that the frequencydomain method has almost an equivalent accuracy to the time-domain method. It should be noted that, because the analytical functions of ground motion accelerations with arbitrary truncated time and its Fourier transform exist in this case, an accurate comparison becomes possible.

\section{CONCLUSIONS}

The following conclusions may be drawn.

(1) The earthquake input energy to a base-isolated building until an arbitrary time $t$ can be expressed in the frequency domain in terms of the Fourier amplitude spectrum of a 
ground motion truncated at the time $t$ and the energy transfer function. The input energy expression in the frequency domain is of the form which can be differentiated analytically by an uncertain parameter.

(2) The earthquake energy input rate at an arbitrary time $t$ can be expressed in the frequency domain in terms of the time derivative of the squared Fourier amplitude spectrum of a ground motion truncated at the time $t$ and the energy transfer function. The time derivative of the squared Fourier amplitude spectrum of a ground motion truncated at the time $t$ is equivalent to the 'instantaneous power spectrum' introduced by Page (1952). The earthquake energy input rate in the frequency domain is of the form easily differentiable by an uncertain parameter.

(3) The proposed frequency-domain method has a reasonable accuracy in the computation of earthquake input energy and energy input rate in comparison with the conventional timedomain method although the response is limited to linear elastic response. Owing to the introduction of Fourier amplitude spectra of 'truncated ground motions', the computational error does not accumulate even at later times in the frequency-domain formulation.

(4) Even higher-order sensitivities of earthquake input energy to a base-isolated structure and those of energy input rate with respect to uncertain base-isolation parameters can be obtained in closed form by taking advantage of the frequency-domain approach. The higher-order sensitivity of the energy transfer function needed in the computation of the higher-order sensitivities of earthquake input energy and input rate can be derived in closed form by using the equations of motion in the frequency domain. It has been confirmed through the comparison with results for the exact model that the proposed method has a reasonable accuracy and its reliability and efficiency are remarkable.

(5) The frequency-domain method has an advantage that the bound analysis of earthquake energy input rate can be implemented easily.

(6) A new model has been proposed of the squared Fourier amplitude spectrum of a ground motion truncated at an arbitrary time. This model enables one to clarify general 
characteristics of earthquake input energy and energy input rate to base-isolated buildings under short-period and long-period ground motions.

It may be difficult to apply directly the frequency-domain method to elastic-plastic problems without approximate treatment such as equivalent linearization methods. The timedomain and frequency-domain methods have different advantages and dual use of these methods may be desired.

\section{ACKNOWLEDGMENTS}

Part of the present work is supported by the Grant-in-Aid for Scientific Research of Japan Society for the Promotion of Science (No.18360264). This support is greatly appreciated.

\section{REFERENCES}

Akiyama H. (1985). Earthquake Resistant Limit-state Design for Buildings. University of Tokyo Press, Tokyo, Japan.

Architectural Institute of Japan (1989, 2001). Recommendation for the design of base isolated buildings.

Ariga T, Kanno Y, Takewaki I. (2006). Resonant behavior of base-isolated high-rise buildings under long-period ground motions. J Struct Design of Tall and Special Buildings, 15(3): 325-338.

Austin M, Lin W-J. (2004). Energy balance assessment of base-isolated structures, J Engng Mech, ASCE; 130(3): 347-358.

Barbat AH, Rodellar J, Ryan EP, Molinares N. (1995). Active control of nonlinear baseisolated buildings. J Engng Mech, ASCE; 121(6): 676-684.

Hall JH, Heaton TH, Halling MW, Wald DJ. (1995). Near-source ground motion and its effect on flexible buildings. Earthquake Spectra, 11: 569-605. 
Heaton TH, Hall JH, Wald DJ, Halling MW. (1995). Response of high-rise and base-isolated buildings in a hypothetical MW 7·0 blind thrust earthquake. Science, 267: 206-211.

Hino J, Yoshitomi S, Tsuji M, Takewaki I. (2008). Bound of aspect ratio of base-isolated buildings considering nonlinear tensile behavior of rubber bearing, Struct Eng \& Mech., 30(3): 351-368.

Housner GW. (1959). Behavior of structures during earthquakes. J Engng Mech Div, ASCE; 85(4): 109-129.

Housner GW, Jennings PC. (1977). The capacity of extreme earthquake motions to damage structures. 'Structural and geotechnical mechanics': A volume honoring NM Newmark edited by WJ Hall, 102-116, Prentice-Hall Englewood Cliff, NJ.

Irikura K, Kamae K, Kawabe H. (2004). Importance of prediction of long-period ground motion during large earthquakes. In Annual Conference of the Seismological Society of Japan, Poster session (in Japanese).

Jangid RS. (1995). Optimum isolator damping for minimum acceleration response of baseisolated structures. Australian Civil Engineering Transactions, 37: 325-331.

Jangid RS, Banerji P. (1998). Effects of isolation damping on stochastic response of structures with non-linear base isolators. Earthquake Spectra, 14: 95-114.

Jangid RS, Kelly JM. (2001). Base isolation for near-fault motions. Earthquake Engng Struct Dyn, 30: 691-707.

Kishida A, Takewaki I. (2006). Exact higher-order sensitivity and variation of earthquake energy input in soil-structure interaction system, Advances in Structural Engineering, 9(5): 653-669.

Kuwamura H, Kirino Y, Akiyama H. (1994). Prediction of earthquake energy input from smoothed Fourier amplitude spectrum. Earthquake Engng Struct Dyn; 23: 1125-1137.

Meirovitch L, Stemple TJ. (1997). Nonlinear control of structures in earthquakes, J Engng Mech ASCE; 123(10): 1090-1095.

Morales CA. (2003). Transmissibility concept to control base motion in isolated structures. Engng Struct; 25(10): 1325-1331. 
Lyon RH. (1975). Statistical Energy Analysis of Dynamical Systems. The MIT Press, Cambridge, MA.

Naeim F, Kelly JM. (1999). Design of Seismic Isolated Structures. Wiley: New York.

Nakamura T, Yamane T. (1986). Optimum design and earthquake-response constrained design for elastic shear buildings, Earthquake Engng Struct Dyn; 14: 797-815.

Ohi K, Takanashi K, Tanaka H. (1985). A simple method to estimate the statistical parameters of energy input to structures during earthquakes. J Struct Construct Engng, AIJ; 347: 47-55 (in Japanese).

Ohi K, Takanashi K, Honma Y. (1991). Energy input rate spectra of earthquake ground motions, J Struct Construct Engng, AIJ, 420: 1-7 (in Japanese).

Page CH. (1952). Instantaneous power spectra, J. Applied Physics, 23(1): 103-106.

Ordaz M, Huerta B, Reinoso E. (2003). Exact computation of input-energy spectra from Fourier amplitude spectra. Earthquake Engng Struct Dyn; 32: 597-605.

Takewaki I. (1998). Hybrid inverse eigenmode problem for a shear building supporting a finite-element subassemblage. $J$ Vibration and Control 4(4): 347-360.

Takewaki I. (2004a). Bound of earthquake input energy. J Struct Engng, ASCE; 130(9): 12891297.

Takewaki I. (2004b). Frequency domain modal analysis of earthquake input energy to highly damped passive control structures, Earthquake Engng Struct Dyn, 33(5): 575-590.

Takewaki I. (2005a). Uncertain-parameter sensitivity of earthquake input energy to baseisolated structure. Struct Eng \& Mech, 20(3): 347-362.

Takewaki I. (2005b). Closure to the discussion by Ali Bakhshi and Hooman Tavallali to 'Bound of Earthquake Input Energy, J Struct Engng, ASCE, 130(9): 1289-1297, 2004', 131(10): 1643-1644.

Takewaki I. (2006). Probabilistic critical excitation method for earthquake energy input rate, $J$. Engng Mech ASCE; 132(9): 990-1000. 
Takewaki I, Fujita K. (2008). Earthquake input energy to tall and base-isolated buildings in time and frequency dual domains, $J$ Struct Design of Tall and Special Buildings, in press.

Trifunac MD, Hao TY, Todorovska MI. (2001). On energy flow in earthquake response. Report CE 01-03, July 2001, University of Southern California.

Uang CM, Bertero VV. (1990). Evaluation of seismic energy in structures. Earthquake Engng Struct Dyn; 19: 77-90. 


\section{Captions of figures and tables}

Table I. Parameters of building and base-isolation system

Table II. Input motion models

Fig.1 $N$-story shear building model supported by base-isolation system

Fig.2 Reduction of MDOF super-structure to SDOF model

Fig.3 Truncated ground motion

Fig.4 Bounding of time-rate of SFAS of truncated ground motion

Fig.5 Energy transfer function of BI model (unit: $\mathrm{N} \cdot \mathrm{s}^{3} / \mathrm{m}$ )

Fig.6 First-order sensitivities of energy transfer function $F(\omega)$ with respect to the stiffness and damping coefficients in the BI story

Fig.7 Second-order sensitivities of energy transfer function $F(\omega)$ with respect to the stiffness and damping coefficients in the BI story

Fig.8 Time history of SFAS at 18(rad/s) of truncated ground motions extracted from El Centro NS 1940 and the corresponding time history of short period model 1

Fig.9 (a) Time histories of input energy for various ground motion models, (b) Time histories of energy input rate for various ground motion models

Fig.10 (a) Variation of maximum energy input rate with respect to base-isolation damping coefficient by first and second-order approximations (long period model 2) and that by full 11DOF model, (b) Variation of mean-square of top acceleration with respect to base-isolation damping coefficient by first, second, third and fourth-order approximations (El Centro NS 1940)

Fig.11 (a) Variation of maximum energy input rate with respect to base-isolation stiffness by first and second-order approximations (long period model 2) and that by full 11DOF model, (b) Variation of mean-square of top acceleration with respect to base-isolation stiffness by first and second-order approximations (El Centro NS 1940)

Fig.12 Frequency distributions of SFAS $\left|\hat{\tilde{U}}_{g}(\omega ; t)\right|^{2}$ of El Centro NS 1940 truncated at (a) 2.5s, (b) 5.0s, (c) 20.0s, (d) 40.0s 
Fig.13 Frequency distributions of time-rates $\partial\left|\hat{\tilde{U}}_{g}(\omega ; t)\right|^{2} / \partial t$ of SFAS of El Centro NS 1940 truncated at (a) 2.5s, (b) $5.0 \mathrm{~s}$, (c) $20.0 \mathrm{~s}$, (d) $40.0 \mathrm{~s}$

Fig.14 A sample of simulated ground acceleration (non-stationary input and stationary input)

Fig.15 Average value of SFAS of 100 ground motions truncated at continuously increasing time: (a) non-stationary input, (b) stationary input

Fig.16 (a) Comparison of time histories of earthquake input energy computed by the timedomain method (Eq.(4)) and the frequency-domain method (Eq.(6)) for non-stationary input, (b) Comparison of time histories of energy input rate computed by the timedomain method $\left(d E_{I}(t) / d t=-\dot{\mathbf{u}}(t)^{T} \mathbf{M} 1 \ddot{u}_{g}(t)\right)$ and the frequency-domain method (Eq.(9)) for non-stationary input 
Table I. Parameters of building and base-isolation system

\begin{tabular}{|c|c|c|c|c|l|}
\hline & plan & $\begin{array}{c}\text { mass } \\
{\left[\mathrm{kg} / \mathrm{m}^{2}\right]}\end{array}$ & mass $[\mathrm{kg}]$ & $\begin{array}{c}\text { horizontal } \\
\text { stiffness }[\mathrm{N} / \mathrm{m}]\end{array}$ & $\begin{array}{c}\text { damping coefficient } \\
{[\mathrm{Ns} / \mathrm{m}]}\end{array}$ \\
\cline { 1 - 5 } $\begin{array}{c}\text { building } \\
(10 \text {-story) }\end{array}$ & $\begin{array}{c}40 \mathrm{~m} \\
\times\end{array}$ & $\begin{array}{c}800 \\
\text { (every } \\
\text { story) }\end{array}$ & $\begin{array}{c}1.28 \times 10^{7} \\
\text { (reduced SDOF } \\
\text { model) }\end{array}$ & $\begin{array}{c}5.05 \times 10^{8} \\
\text { (reduced SDOF } \\
\text { model) }\end{array}$ & $\begin{array}{l}\text { lowest-mode damping } \\
\text { ratio for fixed-base } \\
\text { model=0.02 }\end{array}$ \\
\cline { 1 - 4 } $\begin{array}{c}\text { base- } \\
\text { isolation } \\
\text { story }\end{array}$ & $40 \mathrm{~m}$ & 2400 & $3.84 \times 10^{6}$ & $2.42 \times 10^{7}$ & $\begin{array}{l}\text { damping ratio for rigid } \\
\text { building model=0.2 }\end{array}$ \\
\hline
\end{tabular}

Table II. Input motion models

\begin{tabular}{|c|c|c|c|c|c|c|}
\hline & & $\begin{array}{l}\text { predominant period of } \\
\text { ground or ground } \\
\text { motion } 2 \pi / \Omega \quad \text { (s) }\end{array}$ & $\begin{array}{l}\text { duration } \\
\text { (s) }\end{array}$ & $a$ & $b_{1}$ & $b_{2}$ \\
\hline \multirow{2}{*}{$\begin{array}{l}\text { Short } \\
\text { period } \\
\text { model }\end{array}$} & short period model 1 & 0.6 & 40 & 13.2 & 0.05 & 0.051 \\
\hline & short period model 2 & 0.8 & 40 & 17.6 & 0.05 & 0.051 \\
\hline \multirow{3}{*}{$\begin{array}{l}\text { Long } \\
\text { period } \\
\text { model }\end{array}$} & long period model 1 & 3.0 & 180 & 2.9 & 0.01 & 0.011 \\
\hline & long period model 2 & 5.3 & 180 & 4.8 & 0.01 & 0.011 \\
\hline & long period model 3 & 8.0 & 180 & 7.5 & 0.01 & 0.011 \\
\hline
\end{tabular}




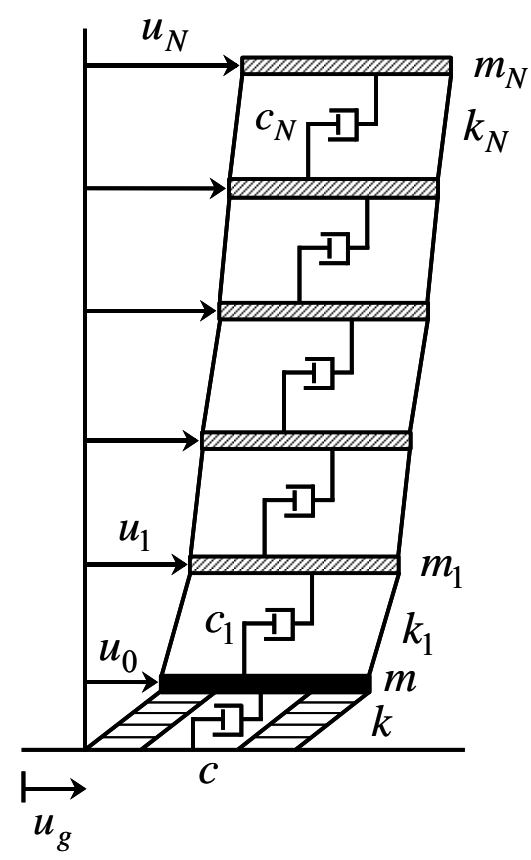

Fig.1 N-story shear building model supported by base-isolation system

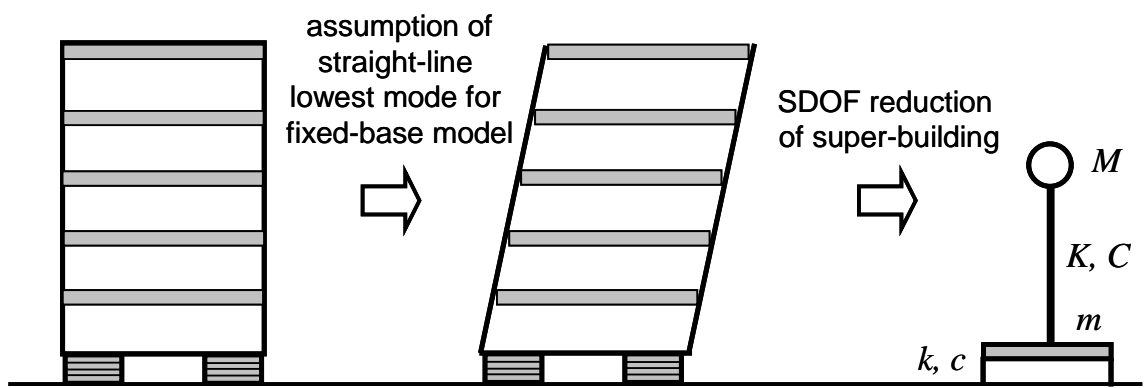

Fig.2 Reduction of MDOF super-structure to SDOF model

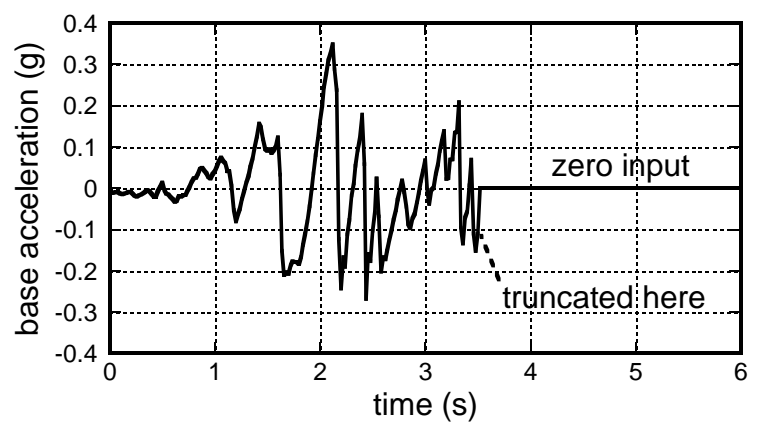

Fig.3 Truncated ground motion 


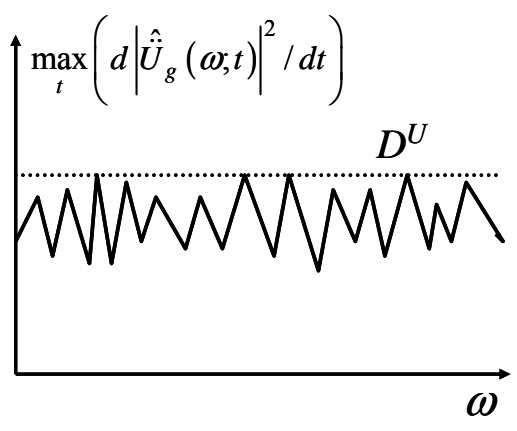

(a) simple model

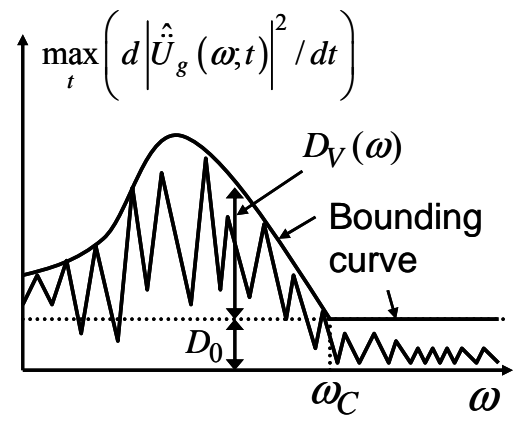

(b) realistic model

Fig. 4 Bounding of time-rate of SFAS of truncated ground motion

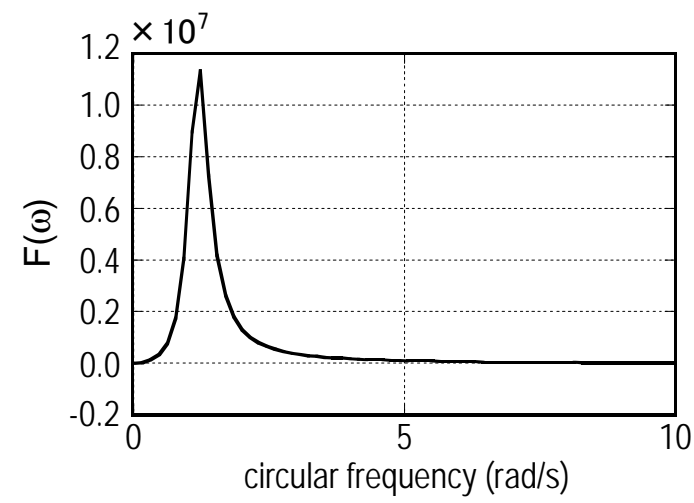

Fig.5 Energy transfer function of BI model (unit: $\mathrm{N} \cdot \mathrm{s}^{3} / \mathrm{m}$ )

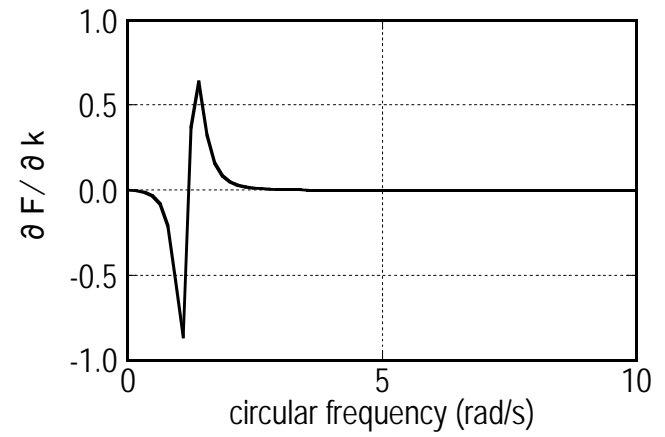

(a) $\partial F / \partial k$

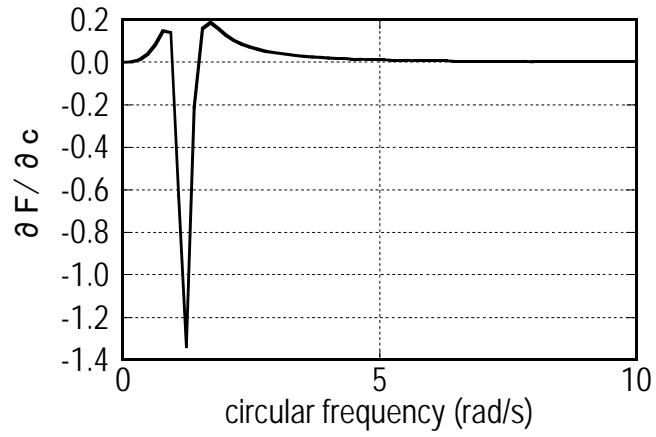

(b) $\partial F / \partial c$

Fig.6 First-order sensitivities of energy transfer function $F(\omega)$ with respect to the stiffness and damping coefficients in the BI story 


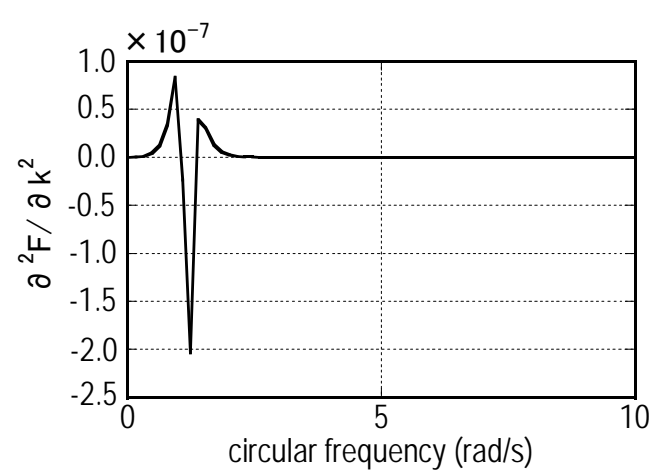

(a) $\partial^{2} F / \partial k^{2}$

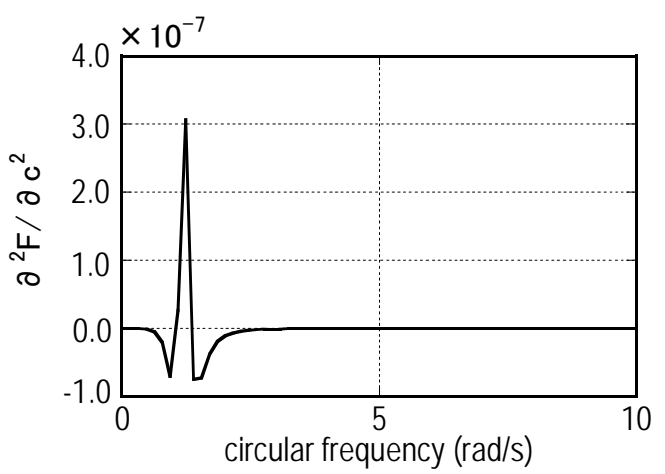

(b) $\partial^{2} F / \partial c^{2}$

Fig.7 Second-order sensitivities of energy transfer function $F(\omega)$ with respect to the stiffness and damping coefficients in the BI story

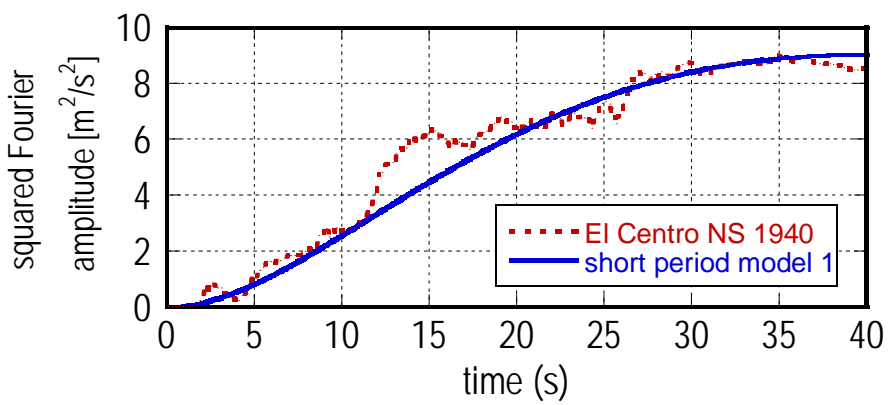

Fig. 8 Time history of SFAS at $18(\mathrm{rad} / \mathrm{s})$ of truncated ground motions extracted from El Centro NS 1940 and the corresponding time history of short period model 1

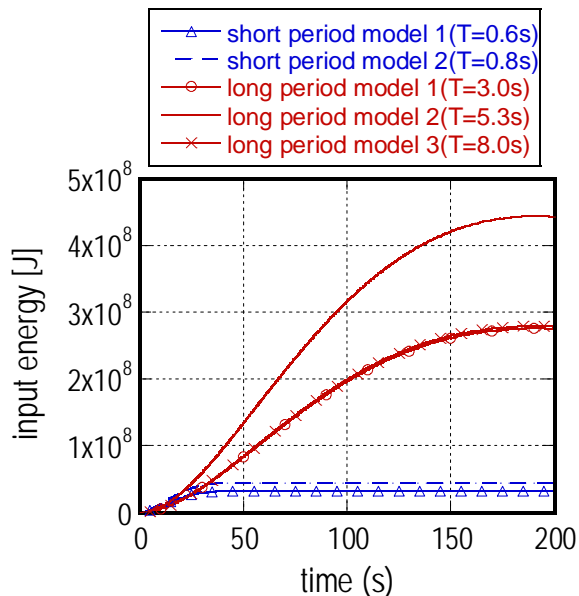

(a)

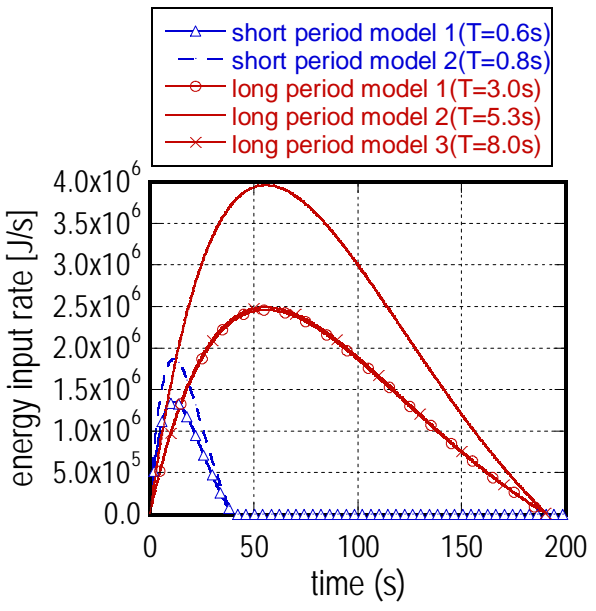

(b)

Fig.9 (a)Time histories of input energy for various ground motion models, (b) Time histories of energy input rate for various ground motion models 

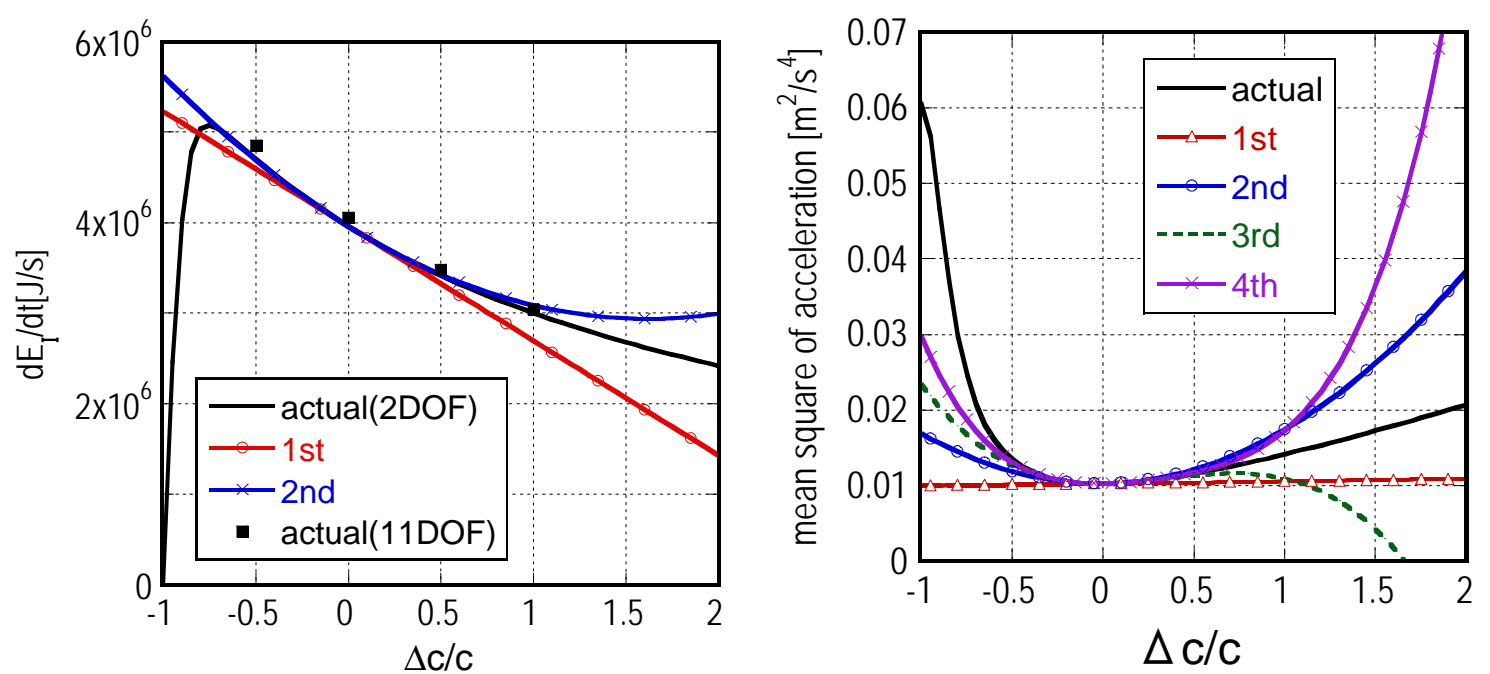

Fig.10 (a) Variation of maximum energy input rate with respect to base-isolation damping coefficient by first-order and second-order approximations (long period model 2) and that by full 11DOF model, (b) Variation of mean-square of top acceleration with respect to base-isolation damping coefficient by first, second, third and fourth-order approximations (El Centro NS 1940)
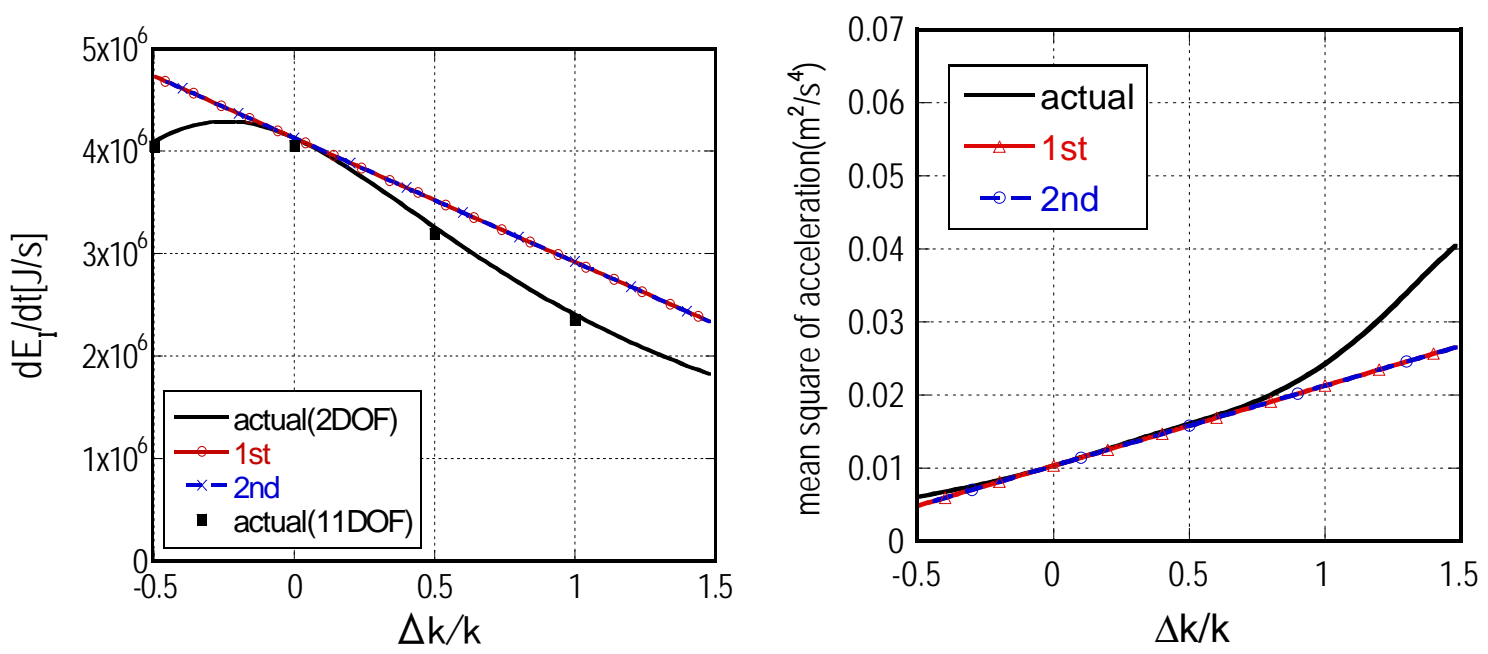

Fig.11 (a) Variation of maximum energy input rate with respect to base-isolation stiffness by first-order and second-order approximations (long period model 2), (b) Variation of mean-square of top acceleration with respect to base-isolation stiffness by first and second-order approximations (El Centro NS 1940) 


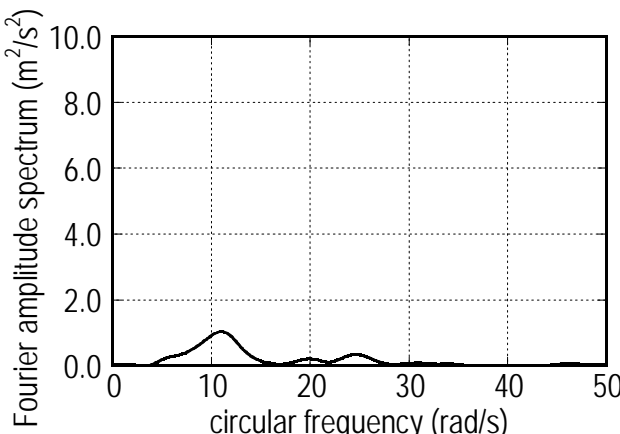

(a)

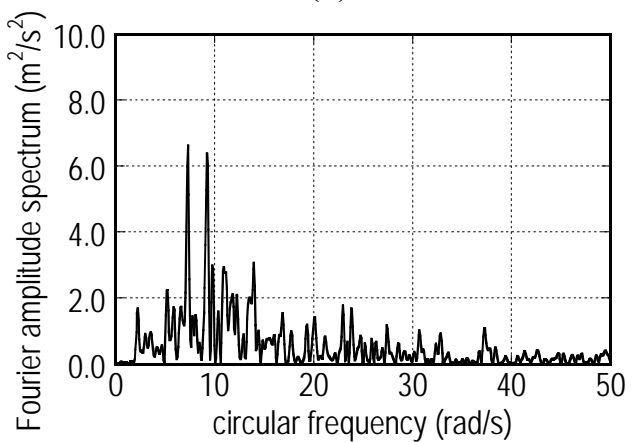

(c)

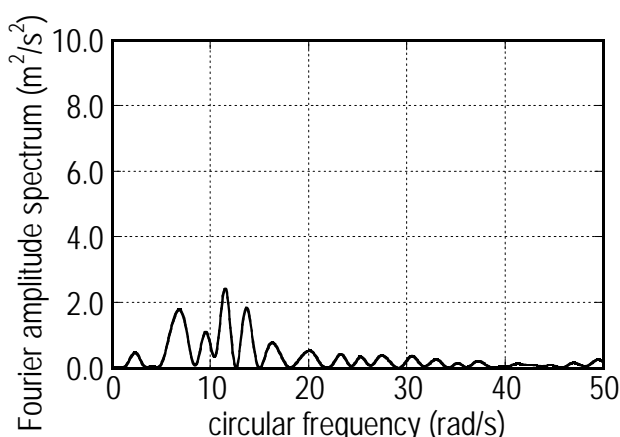

(b)

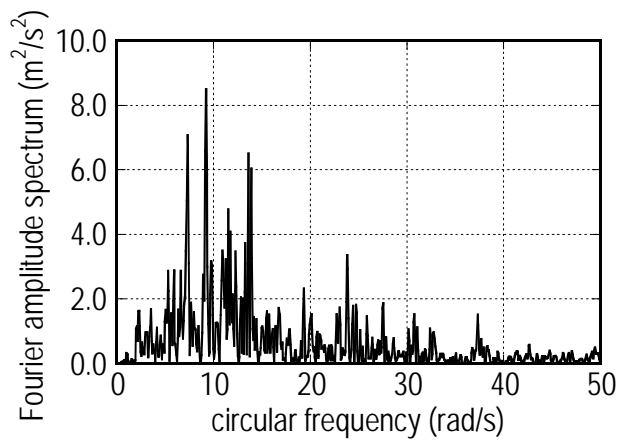

(d)

Fig.12 Frequency distributions of SFAS $\left|\hat{\tilde{U}}_{g}(\omega ; t)\right|^{2}$ of El Centro NS 1940 truncated at (a) $2.5 \mathrm{~s}$, (b) $5.0 \mathrm{~s}$, (c) $20.0 \mathrm{~s}$, (d) $40.0 \mathrm{~s}$

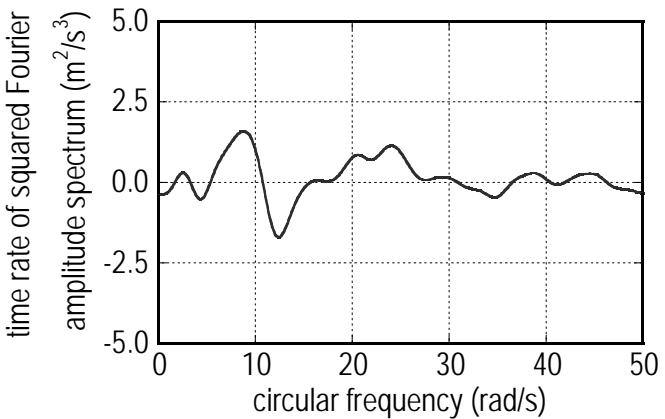

(a)

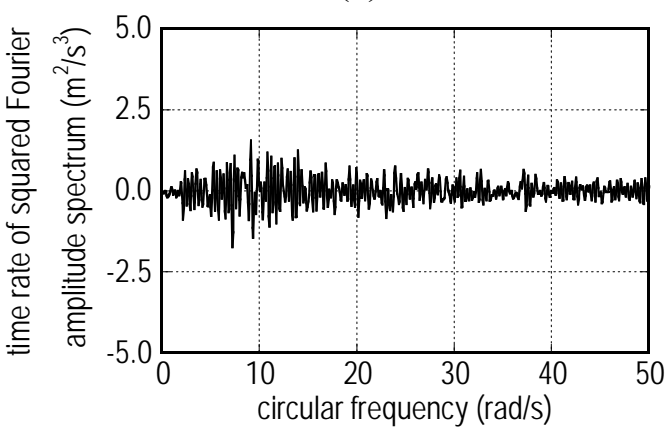

(c)

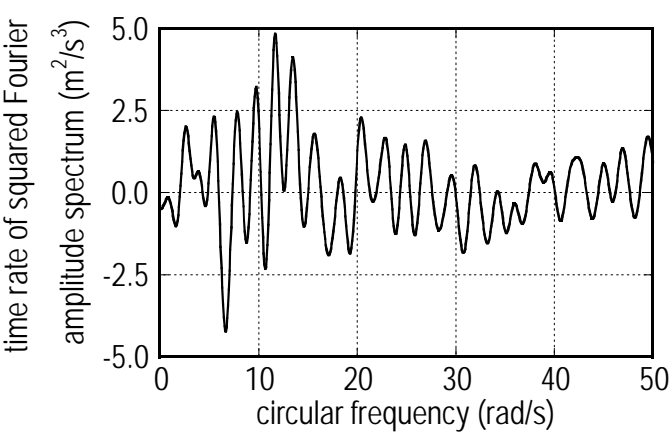

(b)

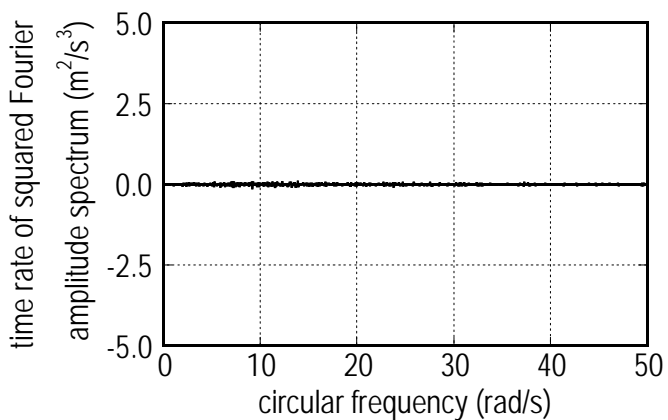

(d)

Fig.13 Frequency distributions of time-rates $\partial\left|\hat{\ddot{U}}_{g}(\omega ; t)\right|^{2} / \partial t$ of SFAS of El Centro NS 1940 truncated at (a) $2.5 \mathrm{~s}$, (b) $5.0 \mathrm{~s}$, (c) $20.0 \mathrm{~s}$, (d) $40.0 \mathrm{~s}$ 


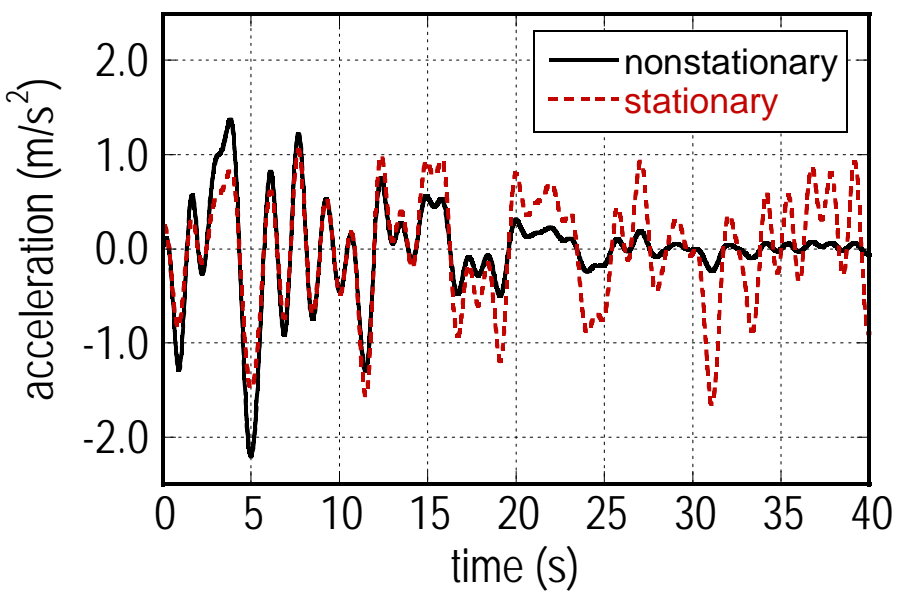

Fig.14 A sample of simulated ground acceleration (non-stationary input and stationary input)

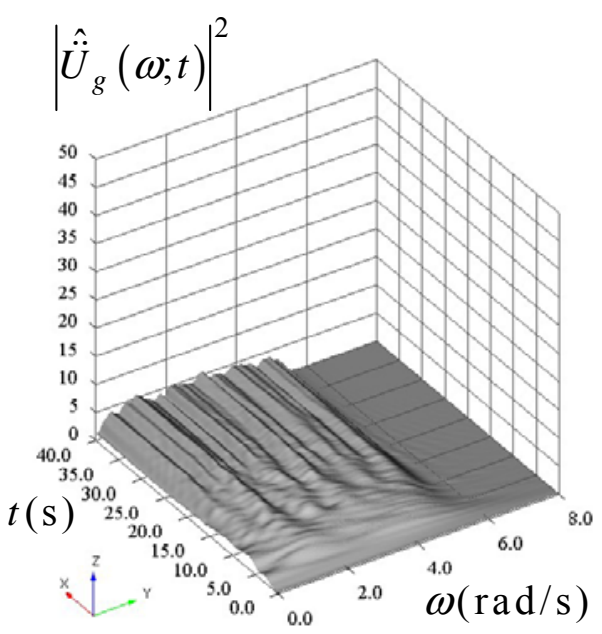

(a)

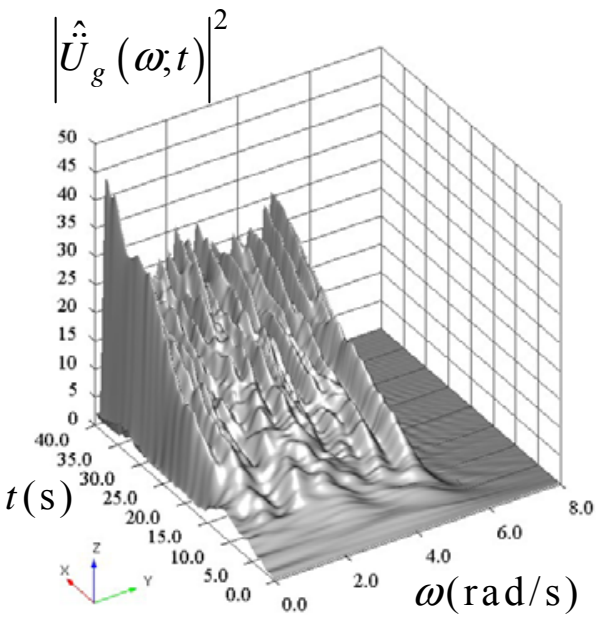

(b)

Fig.15 Average value of SFAS of 100 ground motions truncated at continuously increasing time: (a) non-stationary input, (b) stationary input 


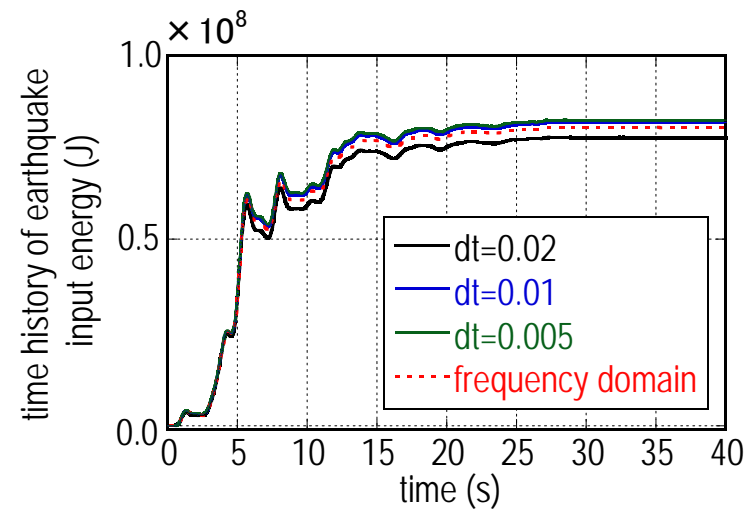

(a)

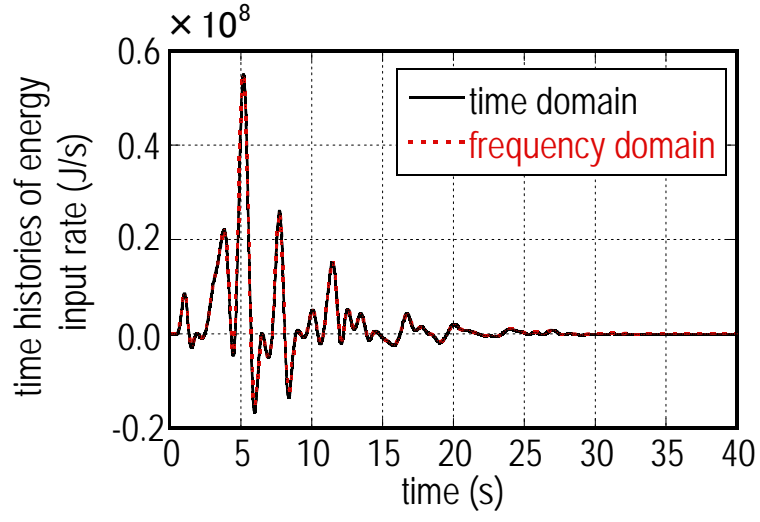

(b)

Fig.16 (a) Comparison of time histories of earthquake input energy computed by the timedomain method (Eq.(4)) and the frequency-domain method (Eq.(6)) for non-stationary input, (b) Comparison of time histories of energy input rate computed by the time-domain method $\left(d E_{I}(t) / d t=-\dot{\mathbf{u}}(t)^{T} \mathbf{M} 1 \ddot{u}_{g}(t)\right)$ and the frequency-domain method (Eq.(9)) for non-stationary input 